\title{
CEU - O componente onomástico na área educacional
}

\section{CEU - The onomastic component in the educational area}

\begin{abstract}
RESUMO: O projeto de educação conhecido como CEU - Centro Educacional Unificado - foi abordado neste contexto como um componente onomástico. Para a Semiótica Discursiva, entende-se por componente onomástico um dos subcomponentes da figurativização capaz de produzir o efeito de sentido "realidade". O lexema CEU (oralizado como céu) pode ser considerado como tal, na medida em que sua verbalização remete a uma configuração discursiva particular nas áreas da Semiótica, Comunicação e Educação. Pretende-se com essa análise mostrar a intencionalidade presente no discurso do poder público municipal de São Paulo, ao nomear uma escola pública com o nome de "CEU".
\end{abstract}

PALAVRAS-CHAVE: Semiótica; Comunicação; Educação.

ABSTRACT: The project of the education know as CEU - Unified Educational Center - was analysied in this research as one component onomastic. On the concept of a Semiotic Discourse, component onomastic can be understood as a subcomponent of figurativizacion capable of produce effects of meaning "reality". The word CEU (oralizied as "sky") can be considered from a methodology point of view of a Semiotic as a configuration the particular discourse, it is necessary to see in the relation between education and communication. Beyond this analysis as presented in Semiotic Discourse the investigation is focused to exam the discourses "intencional" produced by management in the denominate a school public de " $C E U$ ".

KEYWORDS: Semiotic; Communication; Education.

\section{Introdução}

Segundo Algirdas Julien Greimas ${ }^{1}$, a intenção serve para explicar a comunicação enquanto ato, introduz-se geralmente o conceito de intenção, que se supõe motivá-la e justificá-la. Essa noção nos parece criticável, de acordo com Greimas. Assim o teórico diz ser preferível o conceito de "intencionalidade".

Por isso que preferimos o conceito de intencionalidade, de origem claramente fenomenológica, que mesmo não se identificando nem com o de motivação nem com o de finalidade, os subsume: assim, ele permite

\footnotetext{
${ }^{1}$ GREIMAS, Algirdas Julien; COURTÉS, Joseph. Dicionário de Semiótica. Tradução de Alceu Dias Lima et al. São Paulo: Editora Contexto, 2008, p. 267.
} 
conceber o ato como uma tensão que se inscreve em dois modos de existência: a virtualidade e a realização. A formulação semiótica que gostaríamos de dar desse conceito o aproximaria de competência modal. ${ }^{2}$

Perguntamos, existiria uma "intencionalidade" (motivo?) para os idealizadores do projeto do Centro denominá-lo de CEU? Podemos encontrar a resposta em Greimas, quando diz que a "intencionalidade" é interpretada como uma "visada do mundo", com uma relação orientada:

[...] ao mesmo tempo em que recusamos o conceito de intenção (pelo qual alguns tentam fundamentar $o$ ato de comunicação, repousando este numa "intenção de comunicar" - quando mais não fosse porque ele reduz a significação a uma única dimensão consciente (como ficaria então o discurso onírico por exemplo?) -, preferimos o de intencionalidade que interpretamos como uma "visada do mundo", como uma relação orientada, transitiva, graças à qual o sujeito constrói o mundo enquanto objeto ao mesmo tempo em que se constrói a si próprio. ${ }^{3}$

Com o objetivo de apreender a intencionalidade presente no discurso do poder público para denominar o equipamento, inicia-se a análise a partir do que supostamente e/ou culturalmente significa "céu".

No universo cultural religioso, dado a intencionalidade de "um lugar imaginário" das bem-aventuranças para os sujeitos de "bem", criou-se a ideia de um "céu". $\mathrm{Na}$ narrativa religiosa o 'desejo' de conquistar o 'céu' se dá porque os sujeitos crêem nas supostas maravilhas que possam existir nesse 'espaço-lugar' imaginário.

Assim, o "o céu" ou a "ascensão ao céu", pode ser tratado como motivo, "motivo" no sentido de agir, isto é, o "céu" "ou subir ao céu" é um motivo na medida em que é um tema recorrente na cultura ocidental, normalmente caracterizado por configurações discursivas e isotopias figurativas particulares, como "mundo superior", "morada dos deuses" (ou de Deus), "paraíso" etc. Sabe-se também, dado o universo cultural no qual se insere que o espaço - o "céu" - ocupa posições e desempenha funções diferentes do "inferno", por exemplo.

Mas e quando esse motivo surge numa narrativa política ou num programa de política pública para denominar uma 'escola'? Pode ser esse "CEU" um componente considerado diferente daquele encontrado na estrutura discursiva religiosa ou filosófica?

Se a estrutura narrativa - com seus percursos narrativos - é considerada como uma 'invariante', os motivos se apresentam, então, como variáveis e vice-versa: daí a possibilidade de estudá-los em si mesmos, considerando-os como um nível estrutural autônomo e paralelo às articulações narrativas. Nessa perspectiva, podem-se assimilar os motivos às configurações discursivas, tanto no que se refere à sua organização interna própria (no plano semântico e também no sintático), quanto no que concerne à sua integração em uma unidade discursiva maior. ${ }^{4}$

Para a Semiótica Discursiva, entende-se por componente onomástico um dos subcomponentes da figurativização capaz de produzir o efeito de sentido "realidade". O

\footnotetext{
${ }^{2}$ Idem. p. 267.

${ }^{3}$ Ibidem. p. 168.

${ }^{4}$ GREIMAS, Algirdas Julien; COURTÉS, Joseph. Dicionário de Semiótica. Op. cit. p. 323.
} 
lexema CEU (oralizado como céu) pode ser considerado como tal, na medida em que sua verbalização remete a uma configuração discursiva particular, valorizada positivamente (euforicamente) na cultura ocidental: além da noção religiosa apresentada, não apenas a mitologia judaico-cristã, mas outras mitologias ocidentais ditas pagãs associam o céu à "morada dos deuses" (ou "de Deus"), ao "mundo superior", ao "paraíso", o "espaço éter". Portanto, a utilização desse lexema para denominar um projeto governamental de educação pública é um ato discursivo cujas implicações retóricas não podem ser ignoradas.

Do ponto de vista da organização interna do discurso, pode-se considerar a onomástica (...) como um dos subcomponentes da figurativização. Presumido capaz de conferir ao texto o grau desejável de reprodução do real, o componente onomástico permite uma ancoragem histórica que visa a constituir o simulacro de um referente externo e a produzir o efeito de sentido "realidade". 5

Por que CEU? Visando configurá-lo como um lugar repleto de qualidades não "apenas" educacionais, em sentido estrito, entretanto, relacionado a uma concepção educacional diretamente ligada à promoção da cidadania em sentido amplo, o poder público tratou de apresentá-lo por meio do seguinte slogan: "CEUs, mais do que escolas, centros de formação de cidadania”. É também assim que a educação é discursivizada por Freire:

$\mathrm{O}$ enunciado deixa claro que estamos nos referindo a uma certa educação cujo objetivo é a qualidade, uma qualidade fora da educação e não a qualidade primária que a prática educativa tem em si. Uma certa qualidade com que sonhamos. (...) É exatamente quando percebemos que há qualidades e qualidades, enquanto qualidade terciária quer dizer, valor que atribuímos aos seres, às coisas, à prática educativa.

Por outro lado, se faz necessário, neste exercício, relembrar que cidadão significa indivíduo no gozo dos seus direitos civis e políticos de um Estado e que cidadania tem a ver com a condição de cidadão, quer dizer, com o uso dos direitos e o direito de ter deveres de cidadão. ${ }^{6}$

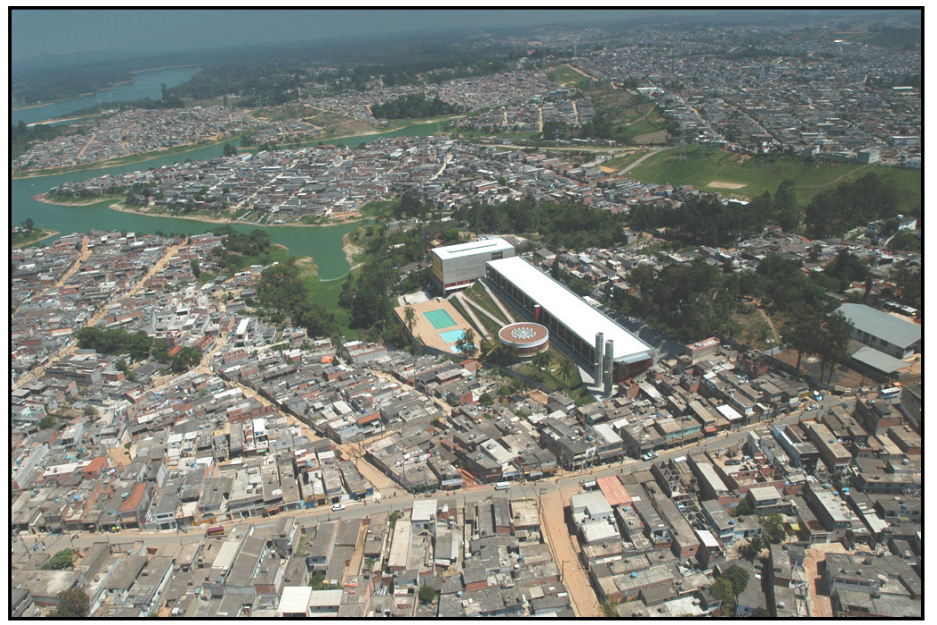

Foto 1: CEU Navegantes - Localização no mapa: Capela do Socorro - Região Sul

5 . Dicionário de Semiótica. Op. cit. p. 350.

${ }^{6}$ FREIRE, Paulo. Política e Educação. Ensaios. 7. Ed.. São Paulo: Cortez Editora, 2003, pp.37-45 


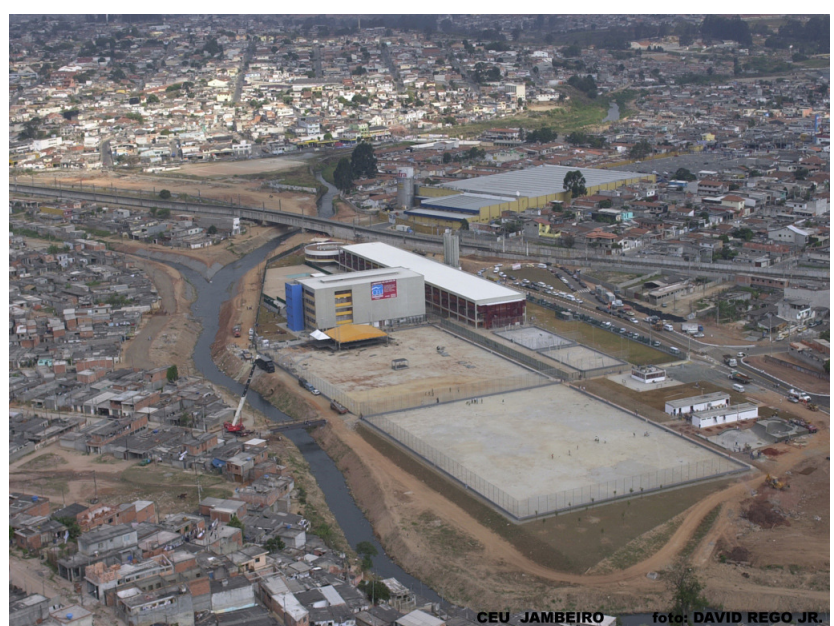

Foto 2: CEU - Jambeiro: a apoteose da estética tecnológica e moderna que avança nos lugares desprovidos de infra-estrutura se estende nos territórios que recepcionam o signo. Ao fundo do CEU um pequeno centro industrial, à frente e ao redor, uma das favelas da região de Guaianazes

Para além dessa força denominativa, para compreender melhor esse componente e o que sobre ele recai enquanto ancoragem histórica e cultural é preciso apreendê-lo na sua relação com os lugares onde foi construído. Para isso e por isso, é preciso ir até ele, não basta simplesmente olhá-lo a distância, em seus aspectos mais exteriores, na condição de projeto ou de objeto de discursos do poder; o CEU deve ser abordado também como lugar, em relação (tensa? conflituosa? harmoniosa?) com outro lugar onde ele passa a existir - no caso, regiões e bairros específicos da cidade de São Paulo.

Portanto, empregar a palavra CEU para denominar uma instituição pública educacional tem a intencionalidade de dar uma importância maior e mais significativa ao equipamento de educação. É subscrever, nas entrelinhas, as mensagens que interessam a um provável público: um espaço planejado para o entrelaçamento de todas as atividades pedagógicas, administrativas, sem, contudo, desconsiderar a participação dos cidadãos do seu entorno na sua construção; por isso, mais um motivo "qualitativo" para ser chamado de CEU: a população ao participar da sua construção vai merecê-lo.

As políticas sociais planejadas para a cidade de São Paulo terão nos CEUs um espaço para o entrelaçamento de atividades de formação que implicam trocas de saberes referentes ao mundo do trabalho e da cultura, bem como possibilidades de realizar atividades que valorizem sua experiência e propicie novos conhecimentos, inclusive do mundo tecnológico, mas observadas as condições da gestão participativa [...]. ${ }^{7}$

Do ponto de vista da análise, o nome pode ser considerado como investimento de um tema, e segundo Greimas, o tema "pode ser reconhecido sob a forma de um percurso (temático) que é uma distribuição sintagmática de investimentos (temáticos) parciais que se referem aos diferentes actantes e circunstantes desse percurso" ${ }^{8}$. Diz o autor que a

\footnotetext{
${ }^{7}$ Prefeitura Municipal de São Paulo. Secretaria Municipal de Educação. Por que os CEUs? Proposta PolíticoPedagógica. Versão preliminar. São Paulo: Maio de 2003, p. 5.

${ }^{8}$ GREIMAS, A. J.; COURTÉS, Joseph. Dicionário de Semiótica. Tradução de Alceu Dias Lima et. al. São Paulo: Editora Cultrix, 1994. p. 453.
} 
tematização pode ser concentrada seja nos sujeitos, seja nos objetos. Nesse caso, o tema se concentra sobre um objeto (um componente da área da política pública), cujo teor semântico se dissemina ao longo do percurso narrativo como: "bondade, justiça social, transparência (a administrativa, logo, incorruptível, por exemplo)" que, pode ser assumido com as posições semânticas. Nesse caso podemos identificar o CEU como um "centro" que chamará para si todos os modos de vida do lugar, do tempo e do espaço da periferia onde se instaura.

Dentre as possibilidades e de conformidade com o nome, pode-se dizer que o lexema CEU é um componente importante na figurativização que a gestão do Partido dos Trabalhadores confere a sua gestão na área educacional, produzindo uma associação discursiva direta entre céu, educação, cidadania e, claro, a gestão pública municipal responsável pelo projeto.

De acordo com Greimas, "o qualitativo figurativo é empregado somente com relação a um conteúdo dado, e, prossegue, é igualmente nessa perspectiva que se entende por percurso figurativo um encadeamento isotópico de figuras, correlativo a um tema dado" 9 . Assim, "CEU", no uso corrente da língua portuguesa, consequentemente cultural, nos remete ao significado popular: "moradia dos bons e dos justos - o espaço éter 10", Tem-se aqui o tema já mencionado: "bondade, justiça, sagrado, incorruptível" etc., e em outra parte o que pode expressar esse tema através de figuras apontadas agora no plano pluriisotópico: áreas de lazer, oficinas de aprendizagem, salas de música, dança etc. Relacionado a essas figuras o plano pluriisotópico nos remete ao "lugar das bem-aventuranças" em consonância com aquelas determinadas ao atendimento do entorno, descritas no discurso dos idealizadores.

Por isso, as palavras Centro Educacional Unificado, ao formar a palavra representada pelo diagrama CEU, passam a significar a idéia relacionada à educação efetiva, benéfica ou mesmo "divina", no lugar onde está instalada - uma suposta "intervenção salvadora", aquela que poderá mudar o "estado do sujeito e do lugar que o detém".

Nas palavras de Pereira, coordenadora de Educação da Subprefeitura da Casa Verde - Cachoeirinha, contidas no documento da SMESP, era preciso fazer desse lugar enunciado, o lugar onde os moradores da cidade pudessem passar de um estado negativo (disfórico), devido às condições de vida em seus bairros, a um positivo (eufórico), o prazer de morar na cidade:

Enquanto equipamento, a contribuição do CEU se associa à ressignificação de espaços intra-muros das unidades, assim como de espaços públicos como praças, entorno de equipamentos revitalizados, que apontem para a construção de uma nova memória na cidade, em que áreas marcadas pela exclusão e pelo descaso, hoje reformadas, possam nos ajudar a potencializar a auto-estima dos moradores desses espaços da cidade, para romper a vergonha em direção ao prazer em morar nessa cidade. ${ }^{11}$

Trata-se, portanto, de um discurso que aparece "positivando" o lugar CEU e "negativizando" a situação dos espaços da cidade e de seus moradores - evidentes aí os respectivos traços de euforia e disforia.

\footnotetext{
${ }^{9}$ Idem, pp. 187-188

${ }^{10}$ Aristóteles acreditava que o Céu era formado por uma substância diferente das coisas sublunares, isto é, pelo éter. O éter, que se move somente por movimento circular, não pode sofrer geração nem corrupção (...). In: Abbagnano, Nicola. Dicionário de Filosofia. Op. cit. p. 133.

${ }^{11}$ PEREIRA, Eliana. Coordenadoria de Educação da Subprefeitura da Casa Verde/Cachoeirinha. Coordenadora de Educação. Documentos apresentados pelas Coordenadorias no Seminário sobre o CEU de São Paulo. Secretaria de Educação do Município: São Paulo: 2004, p. 27.
} 
No fragmento "possam nos ajudar a potencializar a auto-estima dos moradores desses espaços da cidade, para romper a vergonha em direção ao prazer em morar nessa cidade", subentende-se um colocar em presença os sujeitos-moradores do entorno com o CEU como se pretendia no projeto inicial: o CEU em comunicação interna e externa com o entorno. Entretanto, atribui-se aos sujeitos uma situação de contrariedade de estados: os primeiros situados numa categoria - disfórica: vergonha, enquanto o segundo em conformidade com a categoria - eufórica: potência. A diferença está entre o vivido pelo primeiro e o realizado pelo segundo, o que nos permite, pois, estabelecer a análise das modalidades do inferior para o vivido (periferia/abaixo) e do superior para o realizado (CEU/acima).

A partir dessa pressuposição de categorias da ordem do superior para o CEU e do inferior para a comunidade, parece surgir um "conflito" entre o discurso verbal que pretende dotar o Centro de valores freireanos com o discurso manifestado pelo poder público; desse modo parece "ferir" os princípios educacionais propostos a este "lugar".

Por que ferir? - Segundo Paulo Freire, a educação que liberta o sujeito das amarras da tristeza, das relações autoritárias, não se apóia no educador, nem mesmo na escola. Segundo o educador e um dos idealizadores do CEU, a educação é vista do seguinte modo:

[...] a partir das bases de uma pedagogia onde tanto o educador como o educando, homens igualmente livres e críticos, aprendem no trabalho comum de uma tomada de consciência da situação que vivem. Uma pedagogia que elimina pela raiz as relações autoritárias, onde não há "escola" nem "professor", mas círculos de cultura e um coordenador cuja tarefa essencial é o diálogo. ${ }^{12}$

Com o objetivo de identificar alguns traços específicos do processo civilizador, o qual se sabe é diretamente relacionado à história da educação e da civilização moderna, tomamos a idéia de "racionalização" de Norbert Elias, que colabora para a reflexão acerca da compatibilidade ou da incompatibilidade do discurso presente nos ideários freireanos (discurso primeiro), com esse discurso demonstrado do poder público. Porque, bem se sabe que um "motivo" levado ao extremo se torna uma obstinação, ou seja, no ato de obstinação (persistência, insistência) a modalidade do querer-fazer por meio do Centro Educacional Unificado a reversão da história dos lugares, como o seu único 'fazedor', difere da proposta primeira de educação.

Neste sentido, com esse modo de discursivizar o CEU, o poder público pretende uma aproximação, um querer-ser "aliado dos moradores", mas em contrariedade, através do enunciado "aspectualiza" as qualificações de situação de inferioridade organizada sob a forma do arranjo sintagmático: a vergonha.

Não menos característico de um processo civilizador que a racionalização é a peculiar modelação da economia das pulsões que conhecemos pelo nome de vergonha [...] O sentimento de vergonha é uma exaltação específica, uma espécie de ansiedade que automaticamente se reproduz na pessoa em certas ocasiões, por força do hábito. Considerado superficialmente, é um medo de degradação social ou, em termos mais gerais, de gestos de superioridade de outras pessoas. Mas é uma forma de desagrado ou medo que surge caracteristicamente nas ocasiões em que a pessoa que receia cair em uma situação de inferioridade não pode evitar esse

\footnotetext{
${ }^{12}$ FREIRE, Paulo. Educação como prática da liberdade. 29.Ed.. São Paulo: Paz e Terra, 2006, p. 34.
} 
perigo nem por meios físicos diretos nem por qualquer forma de ataque. Essa impotência ante a superioridade dos outros, essa total fragilidade diante deles, não surgem diretamente da ameaça de superioridade física que os demais realmente representem - embora-, sem dúvida, tenha suas origens numa composição física, na inferioridade corporal da criança frente aos pais e mestres, por exemplo. Nos adultos, porém, a impotência resulta do fato de que as pessoas cuja superioridade se teme estão de acordo com o próprio superego da pessoa, com a agência de autolimitação implantada no indivíduo por outros de quem ele foi dependente, que exerciam poder e possuíam superioridade sobre ele. De conformidade com isso, a ansiedade que denominamos de "vergonha" é profundamente velada à vista dos outros. Por forte que seja, nunca é expressada em gestos violentos. A vergonha tira sua coloração específica do fato de que a pessoa que a sente fez ou está ligada de uma forma ou de outra, e consigo mesma, com o setor de sua consciência mediante o qual controla a si mesma. O conflito expressado no par vergonha-medo não é apenas um choque do indivíduo com a opinião social prevalecente: seu próprio comportamento colocou-o em conflito com a parte de si mesmo que representa essa opinião. É um conflito dentro de sua própria personalidade. Ele mesmo se reconhece como inferior. ${ }^{13}$

O sujeito modelado pela vergonha tem medo, não se expõe, não aparenta a coragem necessária para enfrentar os problemas do mundo vivido, é tímido; eis os motivos pelos quais é de praxe nos dizeres de Elias que os aspectos específicos de mudança estrutural da sociedade civilizatória consistem na peculiar tentativa de modelação do outro, afinal, não é menos característico do processo civilizador que a 'racionalização', segundo o autor, seja um processo peculiar de modelação da economia das pulsões ${ }^{14}$. A maneira como o poder público apreende os sentimentos (disfóricos) das periferias e seus moradores, de acordo com o pensamento de Elias, significaria "certa" mudança da sensibilidade, pautada na esteira da pacificação; dado este de certo modo relacionado ao próprio desenvolvimento da educação civilizatória:

Na esteira da pacificação, mudou também a sensibilidade das pessoas à conduta social. Os medos interiores crescem na mesma medida que diminuem os exteriores - os medos de um setor da personalidade no lugar dos de outros. Como resultado dessas tensões internas, as pessoas começaram a sentir experiências umas das outras que haviam sido veladas enquanto enfrentavam constantemente sérias e inescapáveis ameaças de origem externa. ${ }^{15}$

O traço disfórico (a vergonha ou a timidez) projetado aos moradores das periferias e o modo como foi "sensibilizado" e/ou enunciado no discurso do poder público, colabora para o favorecimento do sujeito no seu processo cognitivo? Favorece aquela educação libertária? Não houvesse essas indagações, que nos possibilitam analisar os fatos que parecem contrariar a lógica narrativa do discurso inicial demonstrado na concepção do projeto, os sentimentos não seriam diferentes uns dos outros. Pois, por mais "sensibilizado"

\footnotetext{
${ }^{13}$ ELIAS, Norbert. O processo civilizador. Formação do Estado e Civilização. Teoria dos processos civilizadores. Tradução: Ruy Jungmann. Revisão, apresentação e notas: Renato Janine Ribeiro. Rio de Janeiro: Jorge Zahar Editor, 1993, Vol. 2. p. 242.

${ }^{14}$ Idem.

${ }^{15}$ Ibidem. p. 243.
} 
que possa parecer, o poder ao descrever a potência do CEU e a sua condição de desvelar um outro "sentimento" na comunidade e/ou nos seus moradores - o prazer - por exemplo, ou ao "dotar" o CEU de uma "pretensão" - a de constituir ali naquele espaço um outro lugar, não deixa claras as condições à realização dessa performance. Nesse contexto, de acordo com o pensamento de Paulo Freire o homem moderno "parece" dominado pela força dos mitos e comandado pela publicidade organizada, ideológica ou não, e por isso renuncia, sem o saber, à sua capacidade de decisão.

Uma das grandes, se não a maior, tragédia do homem moderno, está em que é hoje dominado pela força dos mitos e comandado pela publicidade organizada, ideológica ou não, e por isso vem renunciando cada vez, sem o saber, à sua capacidade de decidir. Vem sendo expulso da órbita das decisões. Às tarefas do seu tempo não são captadas pelo homem simples, mas a ele apresentadas por uma "elite" que as interpreta e lhas entrega em forma de receita de prescrição a ser seguida. E, quando julga que se salva seguindo as prescrições, afoga-se no anonimato nivelador da massificação, sem esperança e sem fé, domesticado e acomodado: já não é sujeito. Rebaixa-se a puro objeto. Coisifica-se. ${ }^{16}$

A partir do discurso da administração pública, entende-se que, intencionalmente, ao CEU parece ser dado todo um aspecto valorativo de "glorificação e salvação" dos problemas das periferias, porque a ele é dado o nome de "CEU". Teria esse componente, relação com o discurso da consciência mágica que Freire nos diz?

A consciência mágica, por outro lado, não chega a acreditar-se "superior aos fatos, dominando-os de fora", nem "se julga livre para entendê-los como melhor lhe agradar". Simplesmente os capta, emprestando-lhes um poder superior, que a domina e que a tem, por isso mesmo, de submeter-se com docilidade. ${ }^{17}$

Uma vez na posição de "superior", de um suposto fato "mágico" acontecido na periferia, quando nos referimos à palavra CEU, sua semelhança com o que designamos "céu" revela-se, em uma figura de linguagem: a metáfora, cuja função estilística é própria da figura de palavras. Notadamente, ao explorar a palavra "CEU" nesse caso, procuramos chamar a atenção para a construção do nome que passa a adquirir um novo sentido, uma nova dimensão, uma nova posição no discurso; uma vez que no diagrama - CEU é representada a ideia de similaridade com um outro céu:

[...] assim como a metáfora pressupõe o diagrama e, conseqüentemente, a imagem. (...) a metáfora sempre se engendra num processo de condensação tipicamente diagramático. Para Oliveira é a metáfora que empresta o caráter de visualidade imagética de que se recobre. É ela que faz ver, cria uma imagem mental por força semântica da palavra. ${ }^{18}$

\footnotetext{
${ }^{16}$ FREIRE, Paulo. Educação como prática da liberdade. $29^{a}$ Edição. São Paulo: Paz e Terra, 2006, p. 51.

${ }^{17}$ FREIRE, Paulo. Educação e Conscientização. Op. cit. pp. 113-114.

18 SANTAELlA, Lucia. Matrizes da Linguagem e Pensamento: sonora visual verbal. Aplicações na

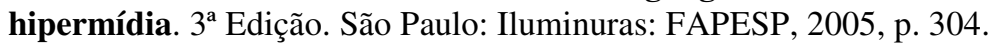




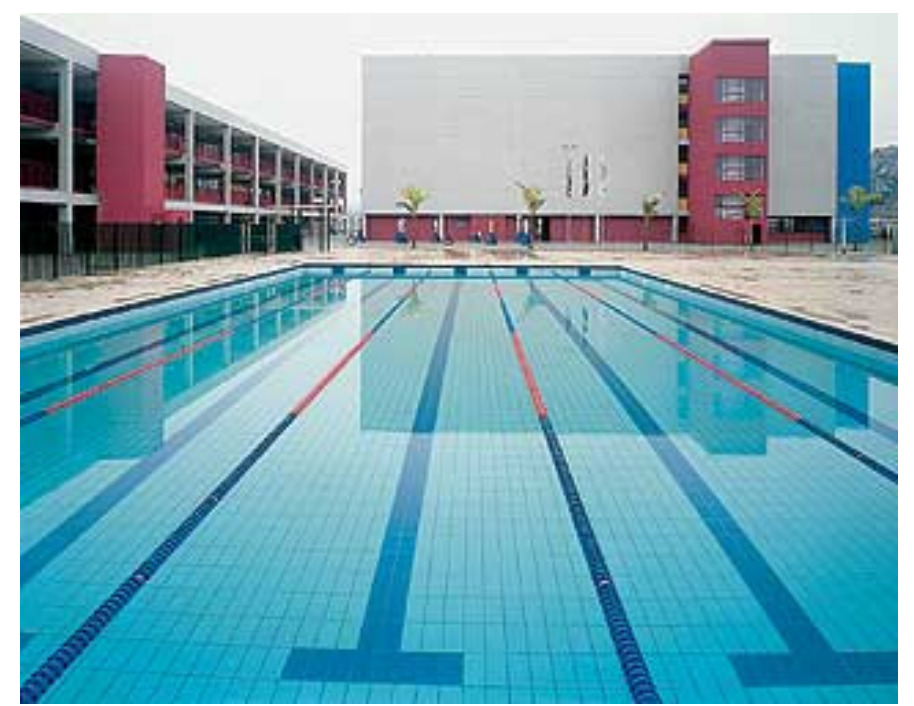

Foto 3 - Piscina do CEU- Jambeiro - Cerca de 1000 pessoas freqüentam os CEUs nos finais de semana. Joffre Dumazedier, considerando a monotonia na vida dos trabalhadores, nos estudos da psicossociologia, inclui as atividades lúdicas, religiosas no conjunto de ocupações do indivíduo. É através das atividades lúdicas oferecidas no prédio do CEU que a vida social da comunidade vê confrontadas, de um lado, as mazelas do lugar, do outro, a área desenvolvida e bem tratada vista no CEU.

A equivalência fônica (CEU/céu) produz um efeito de identificação, devidamente estendida (para além do nome) para uma pretensa similaridade entre os lugares CEU e Céu, associando atributos e valores deste àquele - um processo característico do que a publicidade e a comunicação organizacional chamam de "construção de marca".

O nome CEU vigente num projeto de educação, numa cidade como São Paulo, na medida em que é constituído por uma série de práticas discursivas (denominativa, cultural, política e outras) tende a constituir um modo peculiar de educação característico de doação, gratuidade, superioridade. Trata-se, nesse caso, da construção semiótica de uma identidade, de uma marca, "formada por el conjunto de discursos que mantienem entre si todos los sujetos (individuales o colectivos) que participan em su gênesis" ${ }^{19}$, segundo Andréa Semprini.

Reconhece-se que esta definição de Semprini tem por particularidade, uma abordagem de natureza empresarial, ou seja, embasa-se nos processos de construção e gestão comercial. Contudo, como o próprio título da obra revela: El marketing de la marca. Una aproximación semiótica, toma-se a ideia de Semprini a fim de justificar o fenômeno da marca não circunscrita apenas ao âmbito comercial, mas também ao educacional e ao público e político, porque o que se pretende é projetar um modelo de educação, que supostamente não implica necessariamente um processo de construção de marca tal como ocorre no âmbito do marketing, mas a partir da concepção do nome "CEU" como uma instância de mediação produtora de "outros" discursos que, possivelmente, estão nas estruturas enunciativas.

\footnotetext{
${ }^{19}$ SEMPRINI, Andréa. El Marketing de la marca. Una aproximación semiótica. Barcelona, Espanha: Paidós, 1995, p. 47.
} 
CASA, Vol.7 n.2, dezembro de 2009

\section{Referências bibliográficas}

ABBAGNANO, Nicola. Dicionário de Filosofia. São Paulo: Martins Fontes, 2000.

ELIAS, Norbert. O processo civilizador. Formação do Estado e Civilização. Teoria dos processos civilizadores. Tradução: Ruy Jungmann. Revisão, apresentação e notas: Renato Janine Ribeiro. Rio de Janeiro: Jorge Zahar Editor, 1993, Vol. 2

FREIRE, Paulo. Política e Educação. Ensaios. $7^{\text {a }}$ Edição. São Paulo: Cortez Editora, 2003. FREIRE, Paulo. Educação como prática da liberdade. $29^{\circ}$ Edição. São Paulo: Paz e Terra, 2006.

GREIMAS, Algirdas Julien; COURTÉS, Joseph. Dicionário de Semiótica. Tradução de Alceu Dias Lima et al. São Paulo: Editora Contexto, 2008.

PEREIRA, Eliana. Coordenadoria de Educação da Subprefeitura da Casa Verde/Cachoeirinha. Coordenadora de Educação. Documentos apresentados pelas Coordenadorias no Seminário sobre o CEU de São Paulo. Secretaria de Educação do Município. São Paulo: 2004

Prefeitura Municipal de São Paulo. Secretaria Municipal de Educação. Por que os CEUs? Proposta Político-Pedagógica. Versão preliminar. São Paulo: Maio de 2003.

SANTAELLA, Lucia. Matrizes da Linguagem e Pensamento: sonora visual verbal. Aplicações na hipermídia. $3^{\text {a }}$ Edição. São Paulo: Iluminuras: FAPESP, 2005.

SEMPRINI, Andréa. El Marketing de la marca. Una aproximación semiótica. Barcelona, Espanha: Paidós, 1995. 